\title{
On-Line Monitoring of Cell Growth and Cytotoxicity Using Electric Cell-Substrate Impedance Sensing (ECIS)
}

\author{
Caide Xiao and John H. T. Luong*
}

Biotechnology Research Institute, National Research Council Canada, Montreal, Quebec, Canada H4P 2R2

\begin{abstract}
An on-line and continuous technique based on electric cell-substrate impedance sensing (ECIS) was developed for measuring the concentration and time response function of fibroblastic V79 cells exposed to mercury chloride and 1,3,5-trinitrobenzene (TNB). Attachment, spreading and proliferation of V79 fibroblastic cells cultured on a microarray of small gold electrodes precoated with fibronectin were detected as resistance changes. The response function was derived to reflect the resistance change as a result of cell attachment, spreading, mitosis and cytotoxicity effect. Exposure of V79 cells to mercury chloride or TNB led to alterations in cell behavior, and therefore, chemical cytotoxicity was easily screened by measuring the response function of the attached and spread cells in the presence of inhibitor. The half inhibition concentration, the required concentration to achieve 50\% inhibition, was obtained from the response function to provide information about cytotoxicity during the course of the assay. A simple mathematical model was developed to describe the responses of ECIS that were related to the attachment, spreading, and proliferation of V79 fibroblastic cells. The novel results of this paper are mainly characterized by the systematic study of several parameters including the cell number, detection limit, sensor sensitivity, and cytotoxicity, and they may motivate further research and study of ECIS sensors.
\end{abstract}

\section{Introduction}

The tracking of cell attachment and motility plays an important role in cell biology to elucidate biological phenomena such as cell division, tumor invasion/metastasis, and embryonic cell migration/sorting. To date, very few existing experimental methods can provide quantitative information about cell-substrate interactions in real time. Prior to cell spreading and proliferation, in vitro normal cells secrete extracellular matrix (ECM) proteins and proteoglycans that adhere to a substrate, usually with a slight net negative charge, a condition referred to as anchorage-dependence. The cells then bind to ECM by specific cell surface receptors, and there are gaps or channels (the order of nanometers) between the ventral side of the cell and the substratum (1). This principle has been first exploited by Giaever and Keese toward the development of electric cell-substrate impedance sensing (ECIS) for real-time monitoring cell motion and morphological changes (2). ECIS uses a small gold electrode $(250 \mu \mathrm{m})$ that is microfabricated on the bottom of tissue culture wells and immersed in a culture medium (Figure 1). Inoculated cells drift downward and attach to the electrode surface, precoated with a suitable protein, to form a confluent layer. Except for neuronal cells (3), the attached and spread mammalian cells often act as insulating particles because of their plasma membrane to interfere with the free space immediately above the electrode for current flow. Consequently, there will be a drastic change in the measured impedance due to cell attachment and spreading. An intriguing feature is the fluctuation in the measured impedance, which is

* To whom correspondence should be addressed. Phone: + 514496-6175. Fax: +514-496-6265. Email: john.luong@cnrc-nrc.gc.ca.

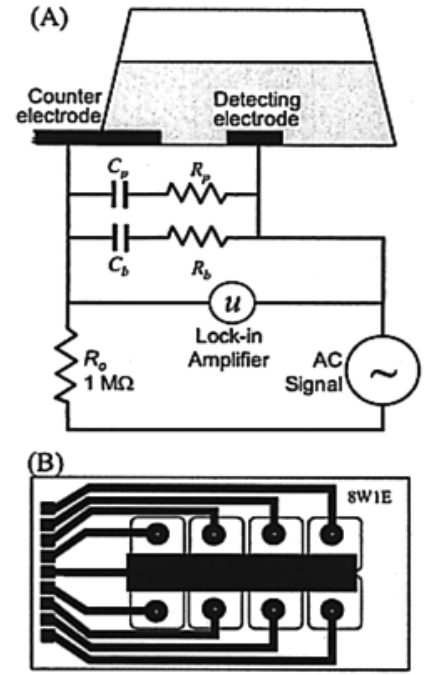

Figure 1. (A) Schematic diagram of electric cell-substrate impedance sensing (ECIS) that was modified with $Z_{\mathrm{b}}\left(R_{\mathrm{b}}=2.21\right.$ $\left.\mathrm{k} \Omega, C_{\mathrm{b}}=4.7 \mathrm{nF}\right)$. (B) Detailed description of the $8 \mathrm{~W} 1 \mathrm{E}$ sensing chip with 8 detecting gold electrodes (circular) and one common counter gold electrode (rectangular).

attributed to vertical motions or micromotions of the cells, an indication of cell viability and morphology change (1, $2-4)$. As cells are sensitive to pollutants, drugs, and toxins, this type of biosensor has been proven as a predictor of cytotoxicity to represent the overall cell response resulting from a variety of inhibition mechanisms. As a versatile and noninvasive tool, ECIS has been able to provide quantitative information with respect to cell morphological changes, cell movements, and alteration in cellular function under various drug, chemical, 
and biochemical treatments $(5-10)$. Recently, integrin receptors have been implicated in the measured impedance of cells attached on different ECM-coated electrodes by Wegener et al. (4). Capacitance change measured at $40 \mathrm{kHz}$ was observed to reflect the attachment and spreading of cells in a linear fashion.

In this study, we establish a mathematical model to describe ECIS responses to the behavior of V79 fibroblastic cells cultured on a microarray of small gold electrodes precoated with fibronectin.A simple and rapid approach is described for on-line monitoring of cell growth and then using cell-substratum interactions as valuable predictors of in vivo response to mercury chloride and trinitrobenzene (TNB) as two test models. Although there have been studies on chemical cytotoxicity using ECIS (10), the present study is the first attempt to provide dynamic information about cytotoxicity during the course of an assay. Since ECIS (9) is only reliable at frequencies between 1 and $10 \mathrm{kHz}$ and resistance increase is more significant than capacitance change, we focus on resistance change at $4 \mathrm{kHz}$ as ECIS responses to cell attachment, spreading, and proliferation. Mercury chloride serves as a model for acute toxicants, whereas TNB represents a model for studying long-term cytotoxicity effects. The inhibition assays provide the inhibitor concentration required to achieve $50 \%$ or half inhibition in real time. Mercury is one of the most toxic substances known to humanity, particularly when it is combined with other atoms and molecules such as the methyl or chloride forms (11). TNB is found at contaminated sites as a byproduct during 2,4,6-trinitrotoluene (TNT) production, and it can be formed through photochemical oxidative degeneration of TNT manufacturing (12). The Resource Conservation and Recovery Act (RCRA) designates TNB as a hazardous waste when it occurs as a discarded commercial product, off-spec species, or spill residue (13).

\section{Materials and Methods}

Materials. Mercury chloride and neutral red (NR) were purchased from Aldrich (Toronto, ON, Canada). Sodium chloride and fibronectin (purity over 99\%) were products of BDH (Toronto, ON) and Sigma (St. Louis, MO), respectively. 1,3,5-Trinitrobenzene (TNB) was supplied by Chem Service (West Chester, PA). Chinese hamster lung fibroblast V79 cells (93-CCL) were purchased from the American Type Culture Collection (ATCC, Rockville, MD).

Cell Culture and Neutral Red Cytotoxicity Assay. A Petri dish inoculated with $\sim 5 \times 10^{5}$ V79 cells was incubated in a humidified incubator at $37^{\circ} \mathrm{C}$ containing $5 \% \mathrm{CO}_{2}$ for $\mathrm{pH}$ control. The Dulbecco's modified Eagle's medium (DMEM; Gibco BRL, Grand Island, NY) for the cell culture was supplemented with $5 \%$ fetal bovine serum (FBS, Sigma). After 48 h, cell suspensions were prepared using $0.05 \%(\mathrm{v} / \mathrm{v})$ trypsin, and cell viability was assessed using the trypan blue exclusion technique (14). The cell population in the suspension was counted for estimating the cellular growth rate. The neutral red (NR) assay was carried out as described by Borenfreund and Puerner (15) with some modifications. The NR stock solution $(20 \mathrm{mg} / \mathrm{mL})$ was prepared in dimethyl sulfoxide (DMSO, Sigma). The NR working solution $(50 \mu \mathrm{g} / \mathrm{mL})$ was prepared by dilution of the stock solution in $10 \mathrm{mM}$ HEPES-buffered DMEM, pH 7.2. Benzalkonium chloride, a germicidal quaternary ammonium compound, was used as reference toxicant in the NR assay.

Electrode Coating and Cell Inoculation. Fibronectin $(0.1 \mathrm{~mL}, 0.1 \mathrm{mg} / \mathrm{mL}$, prepared in $0.85 \% \mathrm{NaCl})$ was admixed into each well to coat the detecting gold electrodes. The chips were placed in the incubator at $37^{\circ} \mathrm{C}$ for $60 \mathrm{~min}$ to ensure complete protein adsorption. After washing the wells with deonized water, $0.2 \mathrm{~mL}$ of culture medium was injected into each empty well, and the impedance baseline of each well was monitored for $4 \mathrm{~h}$. The wells were then emptied and washed with deionized water, and $0.2 \mathrm{~mL}$ of cell suspension $\left(\sim 10^{5}\right.$ cell $\left.\mathrm{s} / \mathrm{mL}\right)$ was inoculated into each well.

Impedance Measurement with ECIS. The sensing chip (8W1E, Applied Biophysics, Troy, NY) consists of eight detecting gold electrodes (circular, $0.057 \mathrm{~mm}^{2}$ ) microfabricated on the bottom of eight separate wells (volume of $\sim 9 \times 9 \times 10 \mathrm{~mm}^{3}$ per well). A common counter gold electrode (rectangular, $7 \times 46 \mathrm{~mm}^{2}$ ) is shared by the eight detecting electrodes on this chip with an area of $2 \times 9 \mathrm{~mm}^{2}$ in each well. Each detecting electrode and the counter electrode are linked with a pad at the edge of the chip (Figure 1). There are two goldliquid interfaces in the well when cell culture medium is added to the well. The impedance $\left(\mathrm{Z}_{\mathrm{s}}\right)$ of the well is equal to the sum of the impedance on the two interfaces and the resistance of liquid between the two electrodes. The impedance of an equivalent circuit with a resistance $\left(R_{\mathrm{s}}\right)$ and a capacitor $\left(C_{\mathrm{s}}\right)$ in series can be used to represent the impedance of the well (9). The impedance of the detecting electrode interface dominates $Z_{\mathrm{s}}$ because the sensing area of the detecting electrode is much smaller than that of the counter electrode $(2,9)$. The two electrodes of the well are connected to a lock-in amplifier of the ECIS system by a $120-\mathrm{cm}$ cable. An alternating potential (AC) is applied to the two electrodes through a $1-\mathrm{M} \Omega$ resistor. The $120-\mathrm{cm}$ cable was reported to contribute a parasitic impedance $\left(Z_{\mathrm{p}}, 1 \mathrm{k} \Omega, 0.19 \mathrm{nF}\right)$, connected in parallel with $\mathrm{Z}_{\mathrm{s}}(9)$. Therefore, there is a noticeable difference between the sample impedance and the impedance measured by the commercial ECIS. A balance impedance $\left(\mathrm{Z}_{\mathrm{b}}, 2.21 \mathrm{k} \Omega, 4.7 \mathrm{nF}\right)$ was used to modify ECIS, so that the resulting system can precisely measure sample impedance between 1 and $10 \mathrm{kHz}$. Detailed information on modified ECIS circuits and impedance measurement can be found elsewhere (9). The main reason for the increasing resistance by attached cells is the isolating properties of their membrane. As the larger changes occur in the resistance, we have only reported and focused on those changes in this study.

Toxicant Addition to Cell Suspension. Mercuric chloride dissolved in $0.15 \mathrm{M} \mathrm{NaCl}$ to a concentration of $10 \mathrm{mM}$ was used as the stock solution. In a doubling dilution series, $0.5 \mathrm{~mL}$ of the stock solution was used to obtain a variety of diluted toxicant solutions. The diluted solutions $\left(C_{n}\right)$ with volume $V(10 \mu \mathrm{L} \leq V \leq 20 \mu \mathrm{L})$ were added to a microtube consisting of $1 \mathrm{~mL}$ of cell suspension $\left(10^{5}\right.$ cells $\left./ \mathrm{mL}\right)$. After thorough but gentle mixing, $0.2 \mathrm{~mL}$ of the resulting solution was introduced to a well on two $8 \mathrm{~W} 1 \mathrm{E}$ sensing chips. The final $\mathrm{HgCl}_{2}$ concentration in a well is estimated as $C_{n} V /(V+1000)$, ranging from 0 to $120 \mu \mathrm{M}$. TNB was dissolved in DMSO, and preliminary studies showed that below $0.35 \% \mathrm{v} / \mathrm{v}$, DMSO exhibited no effect on the V79 NR cytotoxicity assay. Therefore, $10 \mu \mathrm{L}$ of TNB $(0-160 \mu \mathrm{M}$ prepared in DMSO) was added to $5 \mathrm{~mL}$ of cell suspension, so that the resulting DMSO concentration in culture medium was less than $0.2 \% \mathrm{v} / \mathrm{v}$. The toxicant was admixed with the cell suspension just before cell inoculation.

Cell Counting. One hour after inoculation, the chips were taken out of the incubator and placed on an inverted microscope (Wilovert S AFL, Hund, Germany) enhanced with a digital video camera (KP-D50U, Hitachi, Japan). 


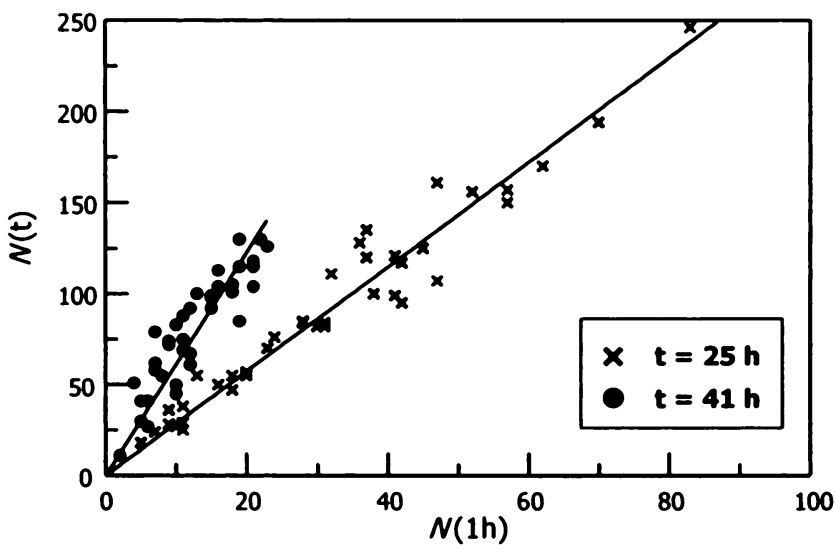

Figure 2. Proliferation of V79 cells in the wells of 8W1E chips. At the beginning the number of cells inoculated on a detecting electrode is $N(1 \mathrm{~h})$, at $t=25$ and $41 \mathrm{~h}$, the number of cells increases to $N(25 \mathrm{~h})=2.87 N(1 \mathrm{~h})$ and $N(41 \mathrm{~h})=6.12 N(1 \mathrm{~h})$.

Digital photos of detecting electrodes were taken, and these photos were used for counting the initial number $\left(N_{0}\right)$ of cells attached on each detecting electrode. The chips were then brought back to the incubator to continue the experiment and the final cell counting was performed at 25 or $41 \mathrm{~h}$. For more prolonged incubation, it was somewhat difficult to have precise cell counting as cells became very thin and flat and were occasionally observed to adhere to their neighboring cohorts. To facilitate cell counting and microscopic examination, EDTA $(0.4 \mathrm{~mL}$, $10 \mathrm{mM}$ in PBS buffer) was added to each well at the end of cell culturing. In the presence of EDTA, cells changed shapes from flat to round in a course of $15 \mathrm{~min}$, and therefore it was easy to distinguish each individual cell attached on the protein coated electrode.

Safety. Mercury chloride and TNB must be handled with extreme care. To avoid inhalation or any skin contact with these chemicals, protective gloves and clothing were worn. Eye protection using safety glasses is included in the recommended respiratory protection. Preparation and handling of these materials were performed in an exhaust hood equipped with ventilation. It is necessary to contain and dispose of these chemicals as hazardous waste.

\section{Results and Discussion}

Mathematical Model for Cell Proliferation. Because ECIS only detects cells that attach and spread on the detecting electrode, it is of importance to determine the cell number $N(t)$ during the course of experiments. In general, cells inoculated in a well require about 30 min to descend to the bottom of the well. After touching the detecting gold electrode precoated with fibronectin, cell-protein adhesion takes place and this process is mediated by a plethora of fibronectin receptors on the cell surface. The experimental data showed that $N(t)$ at $t=25$ and $41 \mathrm{~h}$ were proportional to the initial number $N(1 \mathrm{~h})$ of attached cells as shown in Figure 2.

Considering the time $(\tau)$ required for cells to recover from the disturbance caused by inoculation to a normal growing stage, the cell number on the detecting electrode during the course of experiment should be described as $N(t)=N_{0}(1+\eta)^{t-\tau}$. As $\tau$ is significantly greater than $1 \mathrm{~h}$, the cell number counted at $1 \mathrm{~h}$ into the experiment could be considered as $N_{0}$. Based on the experimental data obtained at 25 and $41 \mathrm{~h}, \eta$ and $\tau$ were estimated to be $4.85 \%$ and $2.7 \mathrm{~h}$, respectively. Therefore, the number of V79 cells growing normally on detecting electrodes coated

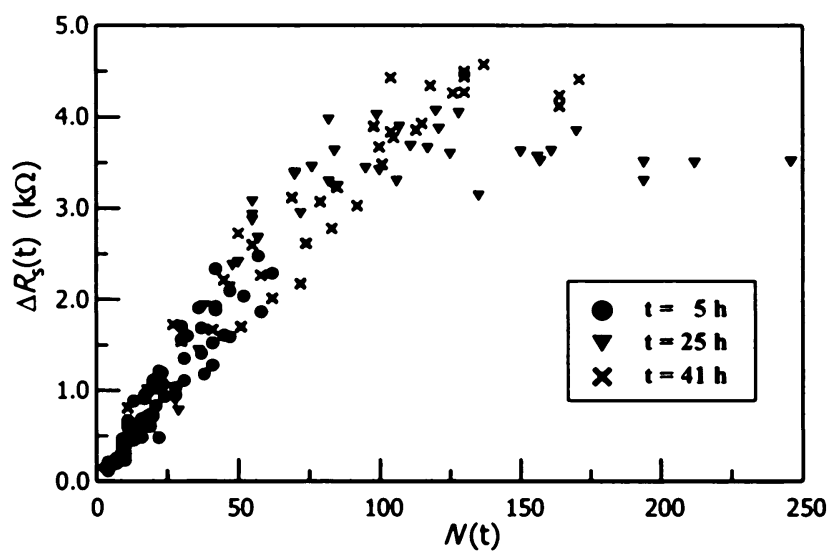

Figure 3. Relationships between resistance change and the number of cells attached on a detecting electrode at $t=5,25$, and $41 \mathrm{~h}$. For $N(t) \leq 80$, the average resistance change contributed by each cell is $41.5 \Omega$.

with fibronectin can be expressed as

$$
N(\mathrm{t})=N_{0}(1+4.85 \%)^{t-2.7}
$$

An independent experiment was also conducted to examine the growth of V79 cells growing in Petri dishes $(\phi 50 \mathrm{~mm})$. After $48 \mathrm{~h}$ of cell culturing, the average ratio between $N(t=48 \mathrm{~h})$ and $N_{0}$ was experimentally determined to be $8.14(n=29, s=1.51)$, which agreed with the value estimated by eq 1 (8.363) for the cell growth in the tissue well. The $t$-test further confirmed that there was no significant difference between the two ratios at $\alpha=0.05$. Therefore, the cell growth in Petri dishes and ECIS tissue wells was confirmed to exhibit the same growth rate with a doubling time of $14.6 \mathrm{~h}$. From the information provided by ATCC Bioresource Center (Manassas, VA), the generation time for V79 is 12-14 h (16).

Responses of ECIS to Cell Number. Although the ECIS system can simultaneously measure sample resistance and capacitance, only the resistance changed significantly during cell culture (figure not shown). Figure 3 described the relationships between resistance change $\Delta R_{\mathrm{s}}(t)$ and the number of cells attached on a detecting electrode at $t=5,25$, and $41 \mathrm{~h}$. For $N(t)<100$, $\Delta R_{\mathrm{s}}(t)$ was proportional to the cell number attached on the detecting electrode, $N(t)$. The average value of $\Delta R_{\mathrm{s}^{-}}$ $(t) / N(t)$ was estimated to be $42.7 \Omega(s=10.1, n=71)$, $44.2 \Omega(s=7.5, n=24)$, and $43.2 \Omega(s=11.7, n=18)$ per cell, respectively. The $t$-test confirmed no significant difference among these averages at $\alpha=0.05$. At the beginning of cell culture $(t \leq 5 \mathrm{~h})$, attached cells were separated from each other, and therefore they could be easily counted. After $25 \mathrm{~h}$ incubation, a majority if not all attached cells formed a confluent film and cells also attached to each other. As the contribution of each cell to $\Delta R_{\mathrm{s}}(t)$ was independent of time, the resistance change during cell culturing was mainly contributed by the number of cells attached on the detecting electrode coated with protein, not due to the cell to cell adhesion.

When $N(t)>100, \Delta R_{\mathrm{s}}(t)$ no longer changed with an increase in the cell number. The minimum number of normal V79 cells to completely cover an 8W1E detecting electrode coated with fibronectin was reported to be 93 from our previous work (9). This result was not completely unexpected with respect to the size of V79 cells $(\sim 30 \mu \mathrm{m})$ vs the surface area of the detecting electrode. The detection limit of ECIS to the number of cells attached on a detecting electrode can be explained by a 
full confluence. Experimental data obtained also illustrated that when $N(t) \leq 80$ and $t=5,25,41 \mathrm{~h}$, the linear relationship was established as $\Delta R_{\mathrm{s}}(t)=41.5 N(t)$ with $r^{2}>0.96$. Consequently, the response function of ECIS using V79 cells $(N(t) \leq 80)$ growing on fibronectin coated $8 \mathrm{~W} 1 \mathrm{E}$ sensing chips can be described as

$$
f(t)=\frac{\Delta R_{\mathrm{s}}(t)}{N_{0}}=41.5(1+4.85 \%)^{t-2.7}
$$

The response function $f(t)$ could be defined as the detection sensitivity of ECIS. At the beginning of cell inoculation in a well on an ECIS chip $(t=0)$, there were no cells on the detecting electrode, so the resistance change was equal to zero. After $\sim 0.5 \mathrm{~h}$, all cells in 0.2 $\mathrm{mL}$ cell suspension descended onto the bottom of the well. While cells were attaching and spreading onto the detecting electrode of the well, the resistance continuously increased with time. About $1 \mathrm{~h}$ into the experiment, the resistance change contributed by each cell attached on the electrode was around 41.5 $\Omega$. During $1<t<\tau$, the resistance of the well did not change significantly. Because mitosis only occurred after $t>\tau$, the increase in the number of cells was governed by eq 1 and up to a certain cell number, the ECIS response should be proportional to the cell number. Figure 4 shows the response functions of the V79 cells with the initial cell number $N_{0}$ $=12,9,11,31,47$ and 83. In general, with the cell number $N(t) \leq 80$ and $\mathrm{t} \geq \tau$, the ECIS response function could be well described by eq 2 as illustrated by the thick and smooth curve in the figure. The validity of eq 2 was confirmed with $N_{0}=31$ and 47 for the estimation of $N(t)$ $=89$ at $25 \mathrm{~h}$ and $N(t)=84$ at $15 \mathrm{~h}$. In these two cases, the ECIS measured data were well described by eq 2 provided the incubation time was less than 25 and $15 \mathrm{~h}$, respectively. Later, the values of these response functions did not change with time significantly due to the formation of the confluent layer. However, when the initial cell number was very high, 83 (last curve from the top), the response function measured $f(t)$ completely deviated from eq 2 (solid curve) right after cell inoculation. For inoculation with high cell populations, the electrode was completely covered by these cells immediately, and the resistance change of the well approached the upper limit $(\sim 4 \mathrm{k} \Omega)$ almost instantly (Figure 3$)$. This was the rationale behind the observation that inoculation with higher initial cell numbers resulted in lower responses in the $\Delta R_{\mathrm{s}} / N_{0}-t$ graph.

It should be noted that the measured response function obtained by ECIS displayed a significant fluctuation to reflect cell motion and viability. The fluctuations of the $\Delta R_{s}(t)-t$ curves reflected cellular events, not inherent noises associated with the ECIS system, because dead cells resulted in very smooth $R_{s}(t)-t$ curves. The fluctuation on the $\Delta R_{s}(t)-t$ curves was related to the number of cells attached on a detecting electrode (Figure 4). These fluctuations were associated with cell endocytosis, phagocytosis, and other cellular activities. During these events, there were materials that diffuse in or out of cells; the conductivity of the cell membrane might change rather randomly. When more cells adhered to the detecting electrode, the random conductivity change of each cell could be averaged, resulting in lower fluctuation. With the present amplifier magnification and modern instrumentation, electrical noise of the ECIS system was significantly below the level of observed fluctuations. Initially, fluctuations in resistance were expected as the cells moved on and off the detecting gold electrode.

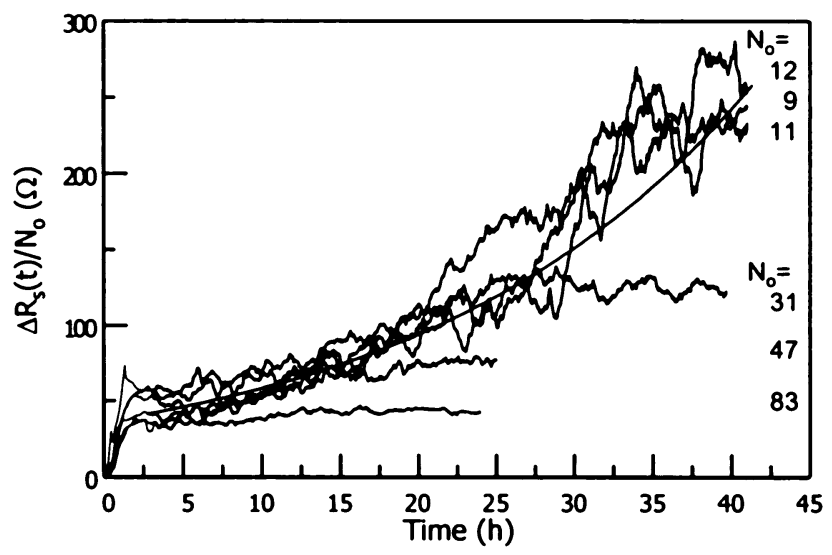

Figure 4. The response functions of ECIS to V79 cells during normal cell culturing procedures. The smooth curve was derived from $f(C, t)=41.5(1+4.85 \%)^{t-2.7}$. The number of initial attached cells $\left(N_{0}\right)$ on the detecting electrode at $t=1 \mathrm{~h}$ is $12,9,11,31$, 47, 83 (top to bottom).

However, the measured fluctuations continued as cell layers become fully confluent, rendering this explanation invalid. On the other hand, the fluctuation will cease when a $1 \%$ formalin solution, a potent cytotoxicant, was added to the cultured well. Such a result confirmed that the fluctuation was associated with the living cells and this was definitely not an artifact of the measurement.

Applications of Response Functions for Cytotoxicity. The adhesion of mammalian cells to ECM protein is mediated by integrins, a family of membrane proteins that plays an important role in cell adhesion. The recognition and specific binding of integrin to ECM are involved in many complex biological processes. If cells are exposed to a toxicant from the very beginning of an ECIS experiment, the cytotoxicity effect to cells can be detected rather rapidly. This is one of the key advantages of ECIS over other techniques for cytotoxicity assays. When a toxicant at the lethal concentration is mixed with the cell suspension and used for inoculating the tissue culture well, the inhibitory effect on attachment, spreading, mitosis, and cytolysis becomes very complex and time-dependent. For an acute toxicant, the majority of cells die instantly and there is no increase in the measured resistance. If cytotoxicity is not very acute, effector cells might still be able to attach and spread on the detecting electrode, leading to an increase in the response function. However, over the lengthy course of toxicant exposure, the attached and infected cells will eventually die and/or cannot bind firmly to the gold electrode, corresponding to a gradual decrease in $f(C, t)$. In the extreme case, the value of the response function $f(C, t)$ approaches zero, an indication of total cell death. In general, the cell growth rate $(\eta)$ will change with time and the toxicant concentration, i.e., $\eta=\eta(C, t)$. Similarly, the contribution of the resistance change by each cell is also a function of time and the toxicant concentration, $k$ $=k(C, t)$. In the presence of a toxicant, the response function measured by ECIS to the cell line should be expressed as

$$
f(C, t)=k(C, t)[1+\eta(C, t)]^{t-\tau}
$$

When cells are instantly killed by the toxicant, $k(C, t)$ will quickly approach zero, and the real time assay can be performed in a very short time. For less acute toxicants, there is no significant change in $k(C, t)$; however, $\eta(C, t)$ still eventually approaches zero as a result of the inhibitory effect of the toxicant on the cell growth. 
The difference of response functions between control and the intoxicated cells might be observed only after many cycles of cell division. In addition, significantly longer time was needed for cytotoxicity assay. Nevertheless, in both cases, the half inhibition of a toxicant to a cell line can be defined as ECIS $_{50}$

$$
\frac{f\left(\mathrm{ECIS}_{50}, t\right)}{f(0, t)}=50 \%
$$

where $f(0, t)$ is the response function measured by ECIS in the absence of the toxicant.

For $\mathrm{HgCl}_{2}$, the cytotoxicity effect was concentrationdependent as expected. Above $80 \mu \mathrm{M}, \mathrm{HgCl}_{2}$ killed V79 cells instantly and the response function $f(82.5, t)$ was measured to be only $10 \Omega$ even after $25 \mathrm{~h}$ into the experiment (Figure 5A). The cytotoxicity effect of $\mathrm{HgCl}_{2}$ on V79 cells was confirmed by microscopic examination of cell counting and morphology. The effector cells subjected to $\mathrm{HgCl}_{2}$ at concentrations above $80 \mu \mathrm{M}$ could not spread on electrodes. In addition, only a few cells with circular shapes were observed on the detecting electrode (photo not shown). Notice that the fluctuation in the measured resistance ceased when the cells were exposed to high $\mathrm{HgCl}_{2}$ levels (above $75 \mu \mathrm{M}$ ). Such killed cell data supported the biological nature of the fluctuation, a unique feature of viable and attached cells as detected by ECIS as discussed earlier. A somewhat similar trend was also observed for V79 cells in the presence of TNB as the division of V79 cells was completely inhibited when TNB reached above $80 \mu \mathrm{M}$ (Figure 5B). However, the response function of $\mathrm{V} 79$ cells displayed a rapid initial drop with an increase in TNB concentration from 6 to $20 \mu \mathrm{M}$, followed by a slow decrease in cytotoxicity with a further increase in TNB concentration from 20 to $120 \mu \mathrm{M}$. Notice also that the assay for TNB was more timeconsuming since the cytotoxicity effect of TNB on V79 cells was only obvious after $20-25 \mathrm{~h}$ into the experiment.

From the response functions obtained at various toxicant concentrations, the value of $f(C, \theta)$ at any given time $t=\theta$ during cell culture was calculated and plotted against $C$ for the estimation of ECIS $_{50}$. With the response functions measured by ECIS, the relationship between the half inhibition concentration $\left(\mathrm{ECIS}_{50}\right)$ and incubation time could be obtained, a unique feature of ECIS (Figure 6 ). The effect of $\mathrm{HgCl}_{2}$ could be seen immediately as described earlier with an average half inhibition concentration of $77.5 \mu \mathrm{M}$. The value then decreased and leveled off at $54.8 \mu \mathrm{M}$ after $25 \mathrm{~h}$ into the assay. However, the inhibitory effect of TNB to V79 cells could only be noticed after $20 \mathrm{~h}$ into the experiment. From 15 to $20 \mathrm{~h}$ after inoculation, ECIS $_{50}$ obtained for TNB to V79 quickly decreased from 160 to $40 \mu \mathrm{M}$ and then leveled off at 6 $\mu \mathrm{M}$ when the experiment was prolonged for another 20 h. From the dynamic toxicity information, it was easy to distinguish the cytoxicicity effects of $\mathrm{HgCl}_{2}$ to $\mathrm{TNB}$. Neutral red assay is usually used to report cytotoxicity at $24 \mathrm{~h}$ after cells are affected by a chemical of interrogation. As illustrated in Figure 7, the half inhibition concentrations measured by neutral red assay denoted as $\mathrm{NR}_{50}$, were compared with ECIS $_{50}$ at $24 \mathrm{~h}$ for five chemicals: cadmium chloride $\left(\mathrm{CdCl}_{2}\right)$, benzalkonium chloride (BAK), sodium arsenate $\left(\mathrm{Na}_{2} \mathrm{HAsO}_{4}\right)$, mercury chloride $\left(\mathrm{HgCl}_{2}\right)$, and TNB. The cytotoxicity data of $\mathrm{CdCl}_{2}$, BAK, and $\mathrm{Na}_{2} \mathrm{HAsO}_{4}$ were obtained from our previous work (10). A linear relationship was derived from the figure: $\operatorname{ECIS}_{50}=1.1 \mathrm{NR}_{50}$ with $r^{2}>0.96$. In the ECIS and NR cytotoxicity assays, the standard deviation of $\mathrm{CdCl}_{2}$ or BAK was smaller than $1 \mu \mathrm{M}$, and the other three

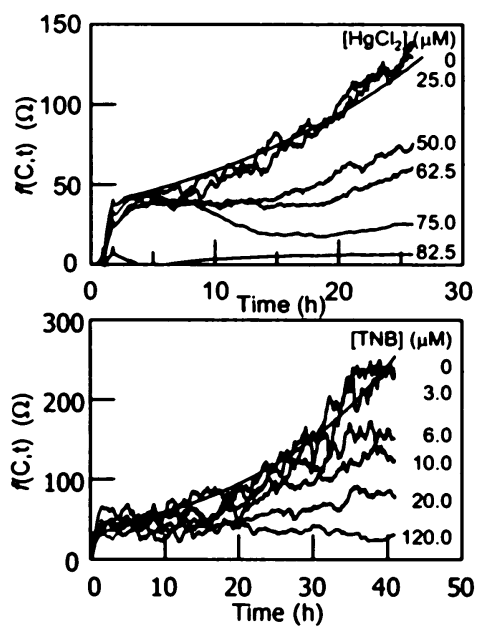

Figure 5. Some selected response functions of V79 cell exposed to (A) $\mathrm{HgCl}_{2}(0,25,50,62.5,75$ and $82.5 \mu \mathrm{M}$, top to bottom) and (B) TNB $(0,3,6,10,20$, and $120 \mu \mathrm{M}$, top to bottom). The two smooth curves were derived from $f(C, t)=41.5(1+4.85 \%)^{\mathrm{t}-2.7}$.

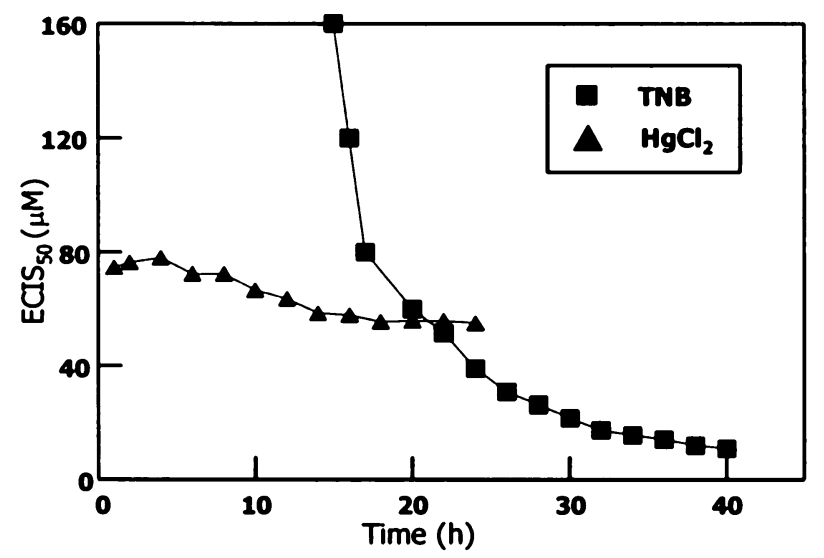

Figure 6. The half inhibition concentration ECIS $_{50}$ as a function of time in the presence of $\mathrm{HgCl}_{2}$ and TNB, respectively.

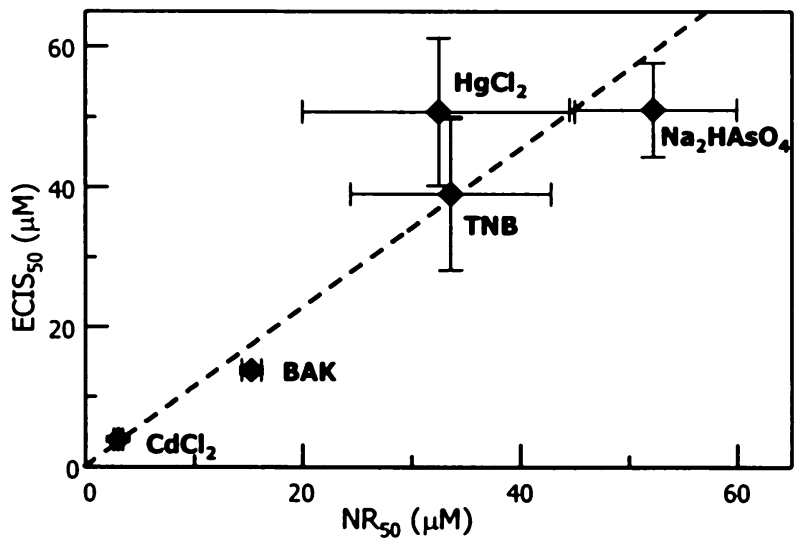

Figure 7. Comparing $\mathrm{NR}_{50}$ (the half inhibition concentrations measured by neutral red assay) and ECIS $_{50}$ at $24 \mathrm{~h}$ after V79 cells incubated with each of five toxicants. Error bars showed the standard deviations of measurements.

chemicals exhibited a value of $\sim 10 \mu \mathrm{M}$. Although similar results were obtained by the two different techniques, only ECIS could provide dynamic cytotoxicity information.

In conclusion, cell growth and division are dynamic and sensitive to environment, especially to toxicants. This study showed that the number of normal V79 cells increased with time and could be described by an 
exponential function. V79 cells attaching and growing on detecting electrodes coated with fibronectin increased the resistance of the well on an ECIS sensing chip. Before cells completely covered detecting electrodes, the resistance change of an ECIS well was proportional to the number of cells attached on the electrodes. As the slope of the linear relationship was constant, the resistance change per initial number of attached cells measured by ECIS could be used to monitor the cell growth in real time. An obvious application of the response function is for on-line cytotoxicity assay of known chemicals or unknown ones in the environment. From response functions of cells subjected to different concentrations of a toxicant, the relationship between half inhibition concentration and time could be obtained to provide dynamic information about cytotoxicity.

\section{Acknowledgment}

The authors would like to thank Dr. Bernard Lachance of the Biotechnology Research Institute, National Research Council Canada for his assistance on the neutral red cytotoxicity assay.

\section{References and Notes}

(1) Heaysman, J. M. E.; Pergum, S. M. In Cell Behavior; Bellairs, R., Curtis, A., Dunn, G., Eds: Cambridge University Press: London, 1982; pp 49-76.

(2) Giaever, I.; Keese, C. R. A Morphological Biosensor for Mammalian Cells. Nature 1993, 366, 591-592.

(3) Borkholder, D. A.; DeBusschere, B. D.; Kovacs, G. T. A. An Approach to the Classification of Unknown Biological Agents with Cell Based Sensors. Technical Digest of the 1998 SolidState Sensor and Actuator Workshop, Hilton Head Island, SC, June 2-11, 1998.

(4) Wegener, J.; Keese, C. R.; Giaever, I. Electric Cell-Substrate Impedance Sensing (ECIS) as a Noninvasive Means to Monitor the Kinetics of Cell Spreading to Artificial Surfaces. Exp. Cell Res. 2000, 259, 158-166
(5) Giaever, I.; Keese, C. R. Toxic? Cells Can Tell. CHEMTECH 1992, 116-125.

(6) Keese, C. R.; Karra, N.; Dillon, B.; Goldberg, A. M.; Giaever, I. Cell-subtratum Interactions as a Predictor of Cytotoxicity. In Vitro Mol. Toxicol. 1998, 11(2), 183-192.

(7) Keese, C. R.; Giaever, I. A Biosensor that Monitors Cell Morphology with Electrical Fields. IEEE Eng. Med. Biol. 1994, 13(3), 402-408.

(8) Luong, J. H. T.; Habibi-Razaei; M.; Meghrous, J.; Xiao, C. D.; Male, K. B.; Kamen, A. Monitoring Motility, Spreading, and Mortality of Adherent Insect Cells Using an Impedance Sensor. Anal. Chem. 2001, 73, 1844-1848.

(9) Xiao, C. D.; Lachance, B.; Sunahara, G.; Luong, J. H. T. An In-depth Analysis of Electric Cell-Substrate Impedance Sensing to Study the Attachment and Spreading of Mammalian Cells. Anal. Chem. 2002, 74, 1333-1339.

(10) Xiao, C. D.; Lachance, B.; Sunahara, G.; Luong, J. H. T. Assessment of Cytotoxicity using Electric Cell-Substrate Impedance Sensing: Concentration and Time Response Function Approach. Anal. Chem. 2002, 74, 5748-5753.

(11) http://www.atsdr.cdc.gov/tfacts46.html, ToxFAQs for Mercury, CAS no. 7439-97-6.

(12) U.S.E.P.A. Support Document for 1,3,5-Trinitrobenzene (TNB), CAS no. 99-35-4. National Center for Environmental Assessment and National Exposure Research Laboratory: Cincinnati, OH, 1997 (http://www.epa.gov/iris/supdocs/tnbsup.pdf).

(13) Dorsey, A.; Llaods, F. ATSDR (Agency for Toxic Substances and Disease Registry); Toxicological Profiles: 1,3-Dinitrobenzene and 1,3,5-Trinitrobenzene. CRC Press: London, 1999.

(14) Freshney, R. Culture of Animal Cells: A Manual of Basic Techniques, A. R. Liss: New York, 1987.

(15) Borenfreund, E.; Puerner, J. A. A Simple Quantitative Procedure using Monolayer Cultures for Cytotoxicity Assays (HTD/NR-90). J. Tissue Cult. Methods 1984, 9, 7-9.

(16) ATCC, the Global Bioresource Center; http://www. atcc.org.

Accepted for publication February 5, 2003.

BP025733X 